C.I.F., T XVII, fasc. 1 y 2 (1991)

\title{
SOME REMARKS ON PRAGMATICS, SCHEMATA AND SECOND LANGUAGE TEACHING
}

\author{
Francisco José Ruiz de Mendoza Ibáñez* \\ Colegio Universitario de La Rioja
}

\begin{abstract}
RESUMEN.-Se debe entender el siguiente artículo como un intento teórico de aclarar los límites conceptuales relativos a los términos "competencia comunicativa" y "capacidad lingüistica". Se espera asi que una mejor comprensión de ambas nociones desde una perspectiva lingüística proporcione al enseñante el fundamento para una reorientación metodológica seria. De tal forma, los principios aquí expuestos se pueden aplicar en la enseñanza de una segunda lengua.

ABSTRACT.-This paper should be understood as a theoretical attempt to clear up the conceptual pathway leading from the notions of ling uistic and communicative competence to that of language capacity. It is expected that a better understanding of such notions from a linguistic perspective will provide the practicioner with solid grounds on which to build the foundations of a methodological reorientation. Thus, the principles expounded here are expected to be applicable to L2 pedagogy.
\end{abstract}

\section{MODERN LINGUISTICS AND METHODOLOGY}

The upheaval created by transformational grammar, which began to affect language pedagogy concerns by the mid-sixties, was followed in the seventies by a feeling of uncertainty among theorists as to the directions of development of L2 methodologies. The previous decades had seen the flourishing and vanishing of a number of methods such as the Intensive Language Teaching of the American Army during World War II, the well-known audiolingual (U.S.A.) and audiovisual (France/Great Britain) methods, the use of the language laboratory and others. Then the interest aroused by the distinction between 'competence' and 'performance', which marked the heyday of

* Dr. en Filología Inglesa. Departamento de Filología Inglesa y Alemana. Universidad de Zaragoza. Colegio Universitario de La Rioja, Caballero de la Rosa, 38. -26004, Logroño. Recibido el 12-6-90. 
psycholinguistic research, resulted in new methodological orientations of a mentalistic sort. Teaching based upon structural drills started to disappear and language learning began to be envisaged as the internalization of rule systems. The learning of syntactic relationships, it was thought, could not be successfully achieved through mere practice with surface structure drills since there were deep structure factors which could deal more effectively with structural similarities, differences and ambiguities. Furthermore, generative grammarians placed a lot of emphasis on the creative nature of language. According to them, a speaker could produce an infinite number of sentences by a limited number of rules. The natural consequence of this principle for language pedagogy was formulated by Diller (1978: 25) as follows: " a language learner does not have to store a large amount of ready-made sentences in his head; he just needs the rules for creating and understanding these sentences".

Transformational grammar was also concerned with the common elements of all languages in contrast to the former structuralist emphasis on the idiosyncrasy of each language -as it was evidenced by the proliferation of contrastive studies such as those by Fries (1952) and Lado (1957). Audiolingualism in pedagogy, behaviourism in psychology and structuralism in linguistics were soon to be overriden by the new emerging rationalism.

In the 1970's Chomsky's views underwent a number of revisions and modifications which affected language methodology once again. An outstanding example of this is the influence of Dell Hymes's (1979) concept of 'communicative competence' on a number of proposals for the elaboration of language teaching syllabuses, which began to incorporate semantic categories of meaning (notions), modality and communicative functions (for example, Wilkins, 1976), as well as syntactic rules. In the same way, the scholars in the Council of Europe Modern Languages Project, on the grounds of semantic and sociolinguistic work, added to this an inventory of situations in terms of learner's roles, settings and topics (van Ek, 1975). It is also worth mentioning a number of projects based on sociolinguistic studies related to Discourse Analysis (Allen and Widdowson, 1974), including Conversational Analysis.

\section{COMPETENCE AND CAPACITY}

In all of the post-structuralist studics mentioned above the objective seems to have been the acquisition by the language learner of native-like competence, whether of a linguistic or a communicative varicty. The notion of linguistic competence, for example, is of central importance to studies in Error Analysis and Interlanguage (Selinker, 1972; Corder, 1981). According to these, an L2 learner's special language can be considered an idiosyn ratic dialect with a number of unstable rules which do not belong to either the mothe: tongue or the target language. The methodological objective would be to enable the learner to bring his language behaviour into line with the conventions of the target language in a process which, it has been suggested, would be natural: the learner, being in contact with the target language, would formulate alternative hypotheses and gradually eliminate the wrong ones. The objective in this 
orientation is therefore the acquiring by the learner of linguistic competence, that is, of linguistic (or grammar) rules.

Criticism against this view by numerous authors (Allwright, 1979; Allen, 1977; Wilkins, 1976; Brumfit, 1979; Finnochiaro and Brumfit, 1983, among others) has been easy on the grounds that teaching a language is teaching how to use it, the target then becoming what is known as the attainment of communicative competence. This would include knowledge not only of grammar rules and vocabulary but also of:

- Rules of speaking, which regulate, for example, when and how to begin or end a conversation, when to speak into it and what to say, how to make use of address forms according to the situation. All these factors have been widely dealt with by studies in Conversational Analysis (eg. Coulthard, 1985).

- How to use and respond to different types of speech acts (promises, requests, apologies, offers, invitations, etc.)

- How to produce utterances which are suitable for the particular situation (what has been termed 'appropriateness').

Although the term 'communicative competence' and its implications have been widely accepted, it has been suggested (Widdowson 1983, 1984) that it should not be treated as a language teaching objective, that, rather, competence is to be achieved through the exercise of what Widdowson has termed 'language capacity', the ability to make meaning at any learning stage with the resources at hand:

The human capacity for making meaning out of linguistic resources is not, then, confined within competence. Nor is it simply converted into competence in the language acquisition process ... We are led to believe that the creative force is channelled into a code and finds expression only in the production of sentences according to rule. But the fact that we are able to produce and interpret utterances which do violence to such rules makes it clear that creative capacity has an independent existence (Widdowson 1984:246)

It is assumed that the learner will tend to accomodate his linguistic behaviour to the norm as he realizes that this will increase his communicative capacity. And capacity is never lost in this process. Capacity does not become competence. It enables the learner to achieve competence.

When we use language to communicate (to make meaning) we make use of all available linguistic resources. But these resources are not confined to rule systems. There are also a number ol principles which guide our production and interpretation of utterances. Now I would like to suggest that these principles, which are in general the concern of pragmatics (see Leech, 1983), are related to the concept of language capacity. This is consonant with the well-known interest of pragmatic studies with the language user, just as it is evidenced by Charles Morris's (1938; see Morris, 1971) original division of semiotics into the study ficlds of 'syntax' (the study of the formal relations of signs to one another), 'semantics' (the relation between signs and objects) and 'pragmatics' (the relation of signs to their interpreters). This is particularly true of Carnap's (1938) understanding of the three fields (as quoted in Levinson, 1983:2-3): 
If in an investigation explicit reference is made to the speaker, or to put it in more general terms, to the user of the language, then we assign it [the investigation] to the field of pragmatics... . If we abstract from the user of the language and analyze only the expressions and their designata, we are in the field of semantics. And, finally, if we abstract from the designata also and anlyze only the relations between expressions, we are in (logical) syntax.

Our assumption here is that we can understand capacity better by studying the nature of pragmatic principles and that these principles, as it will be shown later, are procedural in nature. But before we go into deeper detail, let us try to put into perspective how such principles operate in linguistic comprehension and production.

\section{STRATEGIES, PROCEDURES AND SCHEMATA}

First, we shall make a difference between 'strategies' and 'procedures' in discourse processing. Both are part of our knowledge and must be regarded as an open set. Since they belong, as suggested, to the domain of language capacity (not to competence) they are not rule-governed. They can be taken as working hypotheses about the semantic and syntactic structure of discourse, in other words, a way of making meaning out of discourse. Strategies are sets of procedures engaged upon in the discourse process and they are probably idiosyncratic. For example, consider how a butler might interpret the sentence It's cold in here, uttered by the lord of the manor. In a context in which it is obvious that it is cold this sentence may in principle be considered an unnecessary remark, a breach of one of the maxims of Quantity ("make your contribution as informative as possible") from Grice's Cooperative Principle (see below). But if the lord is supposed to be relevant (Maxim of Relation), the butler will have to attempt to infer the true meaning of the utterance (a request to close an open window, for instance). Maybe something like Labov and Fanshel's so-called 'rule of requests' and 'rule for indirect requests' will hold (see Labov and Fanshel, 1977). These rules are in fact sets of procedures which guide the interpretation of direct and indirect requests, and they are based upon the recognition by both speaker and hearer of a number of preconditions. In our example, the butler might interpret that he is required to close a window (that a request for action was meant by the sentence) if there is a need for the request and a need for the action, if he has the ability and the obligation to perform the action, and if the lord has the right to demand the action. Given these preconditions, the set of pragmatic (nongrammatical) procedures employed in understanding the sentence above might take the following form:

1- Assume S's assertion (A) is relevant

2- Search for any relevant action $X$ to be performed by $H$

3- Analyse the consecuences of performing action $X$

4- If performing action $\mathrm{X}$ cancels the conditions described in $\mathrm{A}$, then hear $\mathrm{A}$ as a request for that action 
This set of procedures can be considered a personal substrategy of the language user, part of a larger strategy or set of strategies activated in discourse. It should be noted that other authors do not make this difference between strategies and procedures (for example, van Dijk and Kintsch, 1983). However, I believe the distinction may be useful. Examine the set of procedures stated above. It is fairly evident that each procedure works on the basis of our world knowledge, that is, knowledge about everyday situations, events and the way they are interrelated. Thus, the butler assumes that what the lord says is relevant because, among other things, people do not tend to supply redundant or too obvious information unless they mean something else. This is the origin of Grice's (1957) well-known distinction between natural and non-natural meaning or "meaning-nn", the latter being equivalent to intentional communication. According to Grice, saying ' $A$ meant ${ }_{\mathrm{NN}}$ something by $x$ ' is roughly the same as saying ' $A$ intended the utterance of $x$ to produce some effect in an audience by means of the recognition of this intention'. In this definition the importance of the intended effect of an utterance is explicitly acknowledged. But such an effect is impossible unless both speaker and hearer share some common background knowledge. For example, in order to understand the intended meaning of $I t$ 's cold in here, the butler needs to know that coldness may disturb his lord as well as how to act in such a situation (what his role as a servant is).

In Artificial Intelligence and cognitive psychology, the kind of knowledge required for procedural principles to operate successfully has been studied under the general name of "schematic knowledge". Thus, 'schemas' or 'schemata' have been proposed as organizing structures which guide much of our memory, abstraction and interpretation processes (see, for example, Alba and Hasher, 1983). As an illustration of the way schemata work in comprehension, the following example (borrowed from Leech 1983: 92) may be useful:
A : In the end we got through the back door.
$\mathrm{B}$ : Did you have to break the lock?

In order for B's answer to be relevant (that is, to enforce the Maxim of Relation), we must assume that the door had a lock which prevented $\mathrm{A}$ from entering. The knowledge that doors have locks is not, strictly speaking, semantic knowledge since this cannot be considered a distinguishing feature of all doors (unlike the fact that a door is used to close an entrance). Since A and B share the same knowledge about doors (and more particularly about a certain door) understanding can take place.

Our knowledge of the world or 'background knowledge' is, we may assume, arranged and disposed for activation at any moment in the discourse process. Although a great deal has been written on the subject, a thorough account of how schemata are organized has not as yet been made and will naturally be beyond the scope of this paper. However a few hints as to their nature not found in the literature on the subject may be useful. In any case for two good reviews on the subject the reader may be referred to Bransford (1979) and Matlin (1989). 
In the interpretation of the utterance We got through the back door we postulated the activation of a door-schema. The activation is possible thanks to a lexical clue (door). Of course schemata do not necessarily function independently (we may invoke several at the same time; eg. a door may be associated with a house, a car, a room, a safe, and so on). But the relevant question is what information is to be included in a given schema. We do not always consider all the details of a concept when it is activated but this does not mean the details are not there. Also, schemata are likely to be highly idiosyncratic, varying from individual to individual. I believe a good approach to the problem is to separate the stable from the unstable features.

Rumelhart and Ortony (1977), in an illustration of what might be a break - schema, specify the following variables: 1) an agent, 2) a (brittle) object , and 3) a method of doing the breaking. Other relevant factors to be taken into account are a change of state of the object (from whole to not whole), a cause and an effect, an instrument, a possible intentionality, etc. Perhaps one way to define the composition of a schema invoked by a lexical item can be derived from a distinction made by Fillmore (1971:282). According to him, the verb accuse presupposes a bad act but asserts that somenone did something, while the verb criticise presupposes that someone did something and asserts the act was bad (John accused Mary of stealing and John criticised Mary for stealing, as the reported versions of, for instance, You stole it! and She shouldn't have stolen it). Both the presuppositions and the assertions can be derived from the lexical meaning of the verbs, and they are independent of other sentential constituents. But the issue is whether presupposition and assertion are part of our schemata. If we use the negation test -as proposed in Kiparsky and Kiparsky (1971)-, we will be able to see that in John didn't accuse Mary of stealing and John didn't criticise Mary for stealing the presuppositions remain constant under negation while the assertions change. Therefore, this type of presupposition will invariably be associated with the lexical item and may be considered a stable constituent of its corresponding schema. This is also true of the break-schema where an agent, an object and a method can be pressuposed. The verb hear presupposes an audible object ( ${ }^{*}$ heard a table) and the verb see that the object is visible (*I saw a thunderclap). All these can be taken to be stable elements of a schema, while in the door example, the existence of a lock cannot be said to be so in the same way.

Generative semanticists (Lakoff, 1970; McCawley, 1971) have postulated a deep structure semantic analysis in terms of 'semantic primitives' which might provide some useful hints too. For example, it is proposed that the verb kill could be analysed as "DO something to CAUSE to BECOME not alive", where DO, CAUSE and BECOME would be semantic primitives belonging to a large number of verbs. This type of analysis may reveal semantic ambiguities, as in I almost killed him, which can be interpreted in three ways:

1- I almost caused him to become not alive

2- I caused him to almost become not alive

3- I caused him to become almost not alive 
The formalization of a cognitive schema for kill should probably include these semantic primitives as stable features, apart from specifying an agent, a method and an animated object (that is, the existence of an agent involves a cause-effect relationship and the effect results from a process of becoming). Such aspects of the meaning of lexical items seem to have been largely ignored by schema theories.

So far it has become apparent that classical semantic analysis is relevant to a schema theory. However semantic theories show a few weaknesses which may be sorted out by reference to a schema theory. Let us try to illustrate this point. The sentence The wind blew would be typical of a number of descriptions. A semantic case analysis -such as those elaborated by Fillmore (1968), and Grimes (1975)- would tell us that the wind is a semantic object (it is in the 'objective' case), while it is a syntactic subject. A usual demonstration of the value of a case grammar will show how a same case can adopt different surface manifestations. The 'instrumental' case, for example, appears both as subject and instrument in Charles opened the door with a key and The key opened the door. But here we are confronted with a problem. We need a set of semantic criteria to be able to decide what case we are dealing with. Thus an 'agentive' may be defined as the "typically animate instigator of an action", an "instrumental' as the "inanimate force or object causally involved" (the entity by means of which an action is carried out), and 'objective' as the entity we describe as being in a state or involved in an action. But how do we really know that the key is instrumental when no surface structure marker indicates so? How is it that we can tell for sure that the key did not open the door by itself? What is it that makes us assume that there is an animate agent involved? -for doors can be opened by natural forces like the wind. One obvious answer is that we recognize a key is an inanimate entity which cannot perform the described action by itself. Our common knowledge of the world includes the information that people open doors with keys. And this simple answer might intuitively be closer to what really goes on in our minds than the notion of selectional restrictions.

Still we can make make one further point in favour of a schema theory. What is it that enables us to understand the meaning of the following two events which are not related by any grammatical marker?:

The wind blew. The door suddenly slammed.

In order to interpret the two sentences coherently we need to assume that the wind is, on the one hand, in the objective case, and on the other hand, that it is to be understood as 'agentive' (or, in other terminologies, as 'force', since it is inanimate). But there is no textual clue whatsoever which facilitates such an interpretation. We can but have recourse to our world knowledge which tells us that the wind can move things. This belongs to the world of our experience. So we draw the inference (if both sentences are to be interpreted as just one utterance) that it was the wind that slammed the door.

The question now is, how do we make such inferences as the one just described? The answer is again quite simple. We make use of our language capacity in order to access information from our background knowledge. An interesting side effect of the 
use of our capacity is the possibility of modifying or increasing the amount of information stored away in our minds in preparedness for use. It is also capacity that enables us to do violence to grammar rules in order, for example, to achieve a conversational goal. This latter aspect is particularly dealt with by pragmatics. In a sense, pragmatic principles sometimes become the bridge between our schematic knowledge and particular situations (when they exist) according to the goals of the language user. Or in other words, the principles which regulate language use are part and parcel of pragmatics.

It has been suggested (Widdowson 1984) that there are two basic types of schemata, 'ideational' (descriptions of objects and situations) and 'interpersonal' (stereotyped sequences of predictable actions). In addition, we find two types of pragmatic principles which regulate the way we make use of our structured world knowledge (or schemata). These principles constitute a type of knowledge different from that of schemata. They are procedures which serve to engage upon schematic knowledge in the discourse process. Some of them have to do with the way we organize the content of our messages for the sake of efficiency and effectiveness in expression. These are textual in nature, such as those stated by Slobin (1979:188-194):
(i)
(iii)
Be clear (Clarity Principle)
(iv) Be processible (Processibility Principle) Be quick and easy (Economy Principle) Be expressive (Expressivity Principle)

In broad outline, the first principle is concerned with transparency and avoidance of ambiguity; the second one with the ordering of the parts of the message; the third one is related to the amount of time and effort involved in encoding and decoding (thus dealing with 'pronominalization', 'substitution' and 'cllipsis'); and the last one involves effectiveness in expression. In consequence, among these principles all relevant aspects of the textual component of a systemic grammar, such as 'thematization' and 'information' (which correspond to 'processibility') and cohesion (which corresponds to 'economy') are adequately dealt with. It must be understood that the principles of 'clarity' and 'expressivity' are largely dependent on the enforcement of maxims (aspects) of the other two. For instance, adequate use of pronominalization, substitution and ellipsis may have a bearing on the clarity and redundancy of a message. Let us take these examples:

(1) Don't kill your wife with work. Let electricty do $i t^{1}$

(2) John Brown was guilty of the crime, and John Brown would have to pay for $\mathrm{it}^{2}$

In (1) the Clarity Principle has been inadvertently violated because of the inadequa-

1.- Taken from Denys Parsons's Fun-tastic (London:Piccolo, 1971), a collection of newspaper mistakes and misprints.

2.-From Joseph Conrad, The Secret Agent, Ch. 12, cited in Leech (1983:68). 
te use of substitution and pronominalization. If we were not aware that it is a mistake, the sentence might be taken, enforcing a procedural principle from the interpersonal rhetoric, as a pun only meaningful on the basis of a piece of our background knowledge about husbands and wifes.

Then in (2) we have a breach of the Economy Principle for the sake of redundancy in order to achieve effectiveness of expression.

While some of the procedural principles are textual, others are interpersonal. Leech (1983), on a survey of the interpersonal rhetoric, states the existence of at least two main principles which can be integrated into the Gricean paradigm of implicature. These are the Cooperative Principle (just as stated by Grice, 1975) and the Politeness Principle. The maxims of the Cooperative Principle are:

Quantity: Make your contribution as informative as possible. Do not be more informative than required.

Quality: Do not say what you believe to be false. Do not say that for which you lack adequate evidence.

Relation: Be relevant.

Manner: Be perspicuous. Avoid obscurity and ambiguity. Be brief, orderly and polite.

The maxims of the Politeness Principle would include a number of variables such as tact, generosity, approbation, modesty, agreement, sympathy, and phatic communion among others. An apparent breach of one of the maxims of the Cooperative Principle may involve the enforcing of a maxim from the Politeness Principle (or from any other principle, like Irony).

If I say John's a fine friend and it is obviously a lie I may seem to be flouting one of the maxims of Quality, but at the same time the hearer of the message will probably interpret it as an ironical remark. Another typical example of the flouting of the maxims of the Cooperative Principle can be illustrated by the following exchange:

\section{A: Let's go to the movies \\ B: I have an examination in the morning}

The apparent irrelevance of B's remark is considered to be a breach of the Maxim of Relation, but it gives way to politeness (thus avoiding an overt refusal) by means of an excuse. Incidentally, the excuse is based on a piece of background knowledge shared by both interlocutors: when someone has an examination the next day, he is likely to want to study and may not have enough spare time for other activities. In the present case, the Tact Maxim is enforced.

From all the above examples, it might be suggested that the maxims of the Cooperative Principle will usually work in relation to ideational schemata, while those of the Politeness Principle, the Irony Principle and the Interest Principle, are more liable to engage on interpersonal schemata. Specially, a breach of one of the maxims of the 
Cooperative Principle will normally make the language user enforce an appropriate interpersonal principle. For example, the Maxim of Modesty ("minimize self-praise; maximize self-dispraise") controls the expression How stupid of me! (which violates one of the maxims of Quality). It is based on the knowledge that attributing a mistake to oneself rather than blaming someone else is part of the conventions which regulate polite social contact. And this is interpersonal knowledge.

\section{CAPACITY AND METHODOLOGY}

The account given above is not complete but it provides certain important clues as to the relationship between competence and capacity, the former being related to forms of declarative knowledge -a pool of passive information, ideational and interpersonalwhile capacity is operational know-how (interpersonal and textual) regulated by pragmatic forces (like the conversational aims of being polite, ironical, cooperative, clear, expressive, and so on). It is important for the language teacher, as well as for the syllabus designer, to be aware of all these facts. Capacity may be not only a theoretical concept but also a reality which a good language methodology might exploit in at least two different ways. First, as Widdowson himself has suggested, since an L2 learner's conceptual patterns are different from those in the target language speakers' minds, and some alignment is needed, it might be useful to try to use his own mother tongue capacity in order for him to build the necessary L2 strategies into his transitional competence. Second, since the relationship between pragmatic knowledge and grammatical form varies with the language it might be useful to help the language learner become aware of such facts in a systematic way. That would enhance his performance potential in the second language. For example, if we only teach grammar we may explain that the verb must is a modal auxiliary which expresses obligation. Then, if we teach functions, we are likely to add the information that in certain situations must is used to express a certain speech act, like an invitation (eg. You must come and have dinner with us, in the same way as We would be pleased if you came and had dinner with us or You will come and have dinner with us, won't you?). But there is still the further possibility that we teach our students a little bit more: * We must come and have dinner with you could -depending on the context- be taken as a hilarious, ironical or impolite remark, or simply a breach of the Tact Maxim of the Politeness Principle. This may not be evident to L2 students unless we help them realize since they may not share the same set of cultural conventions (that is the same ideational and interpersonal schemata) with native speakers of the target language.

Also, when trying to trace the origin of some learners' mistakes, language teachers should be aware that misusing textual principles may result in oddities which do not necessarily reflect a deficiency in grammatical competence. Take the following cases which reflect native-like competence but, in their context, are by no means good examples of language use:

These two sentences violate the maxims of the Clarity Principle?: 
Woman wants cleaning three days a week

Wanted- man to take care of cow that does not smoke or drink

These others result from the misapplication of the Economy Principle:

Wanted-edible oil technologist ${ }^{4}$

If the baby won't drink the milk it should be boiled ${ }^{5}$

The following is grammatically correct, but also a violation of the Processibility Principle:

That the demonstrators were not willing to give in to threats from government officials and abandon their strike at a moment in which they were receiving important and encouraging back-up from most of the parties of the Opposition and in which significant public support was being attracted by them is a fact.

To conclude, it may be pointed out that an L2 learner's requirements should extend beyond the ability to express content and to produce situationally adequate utterances; learning how to use the target language in a clear, effective way entails much more than developing 'competence' in the traditional sense. That is why it may be hoped that an adequate understanding of the relationship between competence and capacity will be useful in helping the learner to meet these requirements.

\section{REFERENCES}

Alba, J. W. \& Hasher, L.1983. "Is memory schematic?". Psychological Bulletin, 93: 203-231.

Allen, J. P. B. \& Widdowson, H. G.1974. "Teaching the communicative use of English". IRAL, $12: 1-21$.

Allen, J. P. B.1977. "Structural and functional models in language teaching". TESL 8.

Allwright, R. L. 1979. "Language learning through communication practice", in Brumfit \& Johnson, 1979: 167-182.

Anderson, R. C., Spiro, R. J. \& Montague, W.E. (eds.).1977. Schooling and the Acquisition of Knowledge. Hillsdale, NJ.: Lawrence Erlbaum.

Bach, E. \& Harms, R.J. (eds.).1968. Universals in Linguistic Theory. New York: Holt, Rinehart \& Winston.

Bransford, J. D.1979. Human Cognition. Learning, Understanding and Remembering. Belmont, CA.: Wadsworth Publishing.

Brumfit, C.J. \& Johnson, K. (eds.).1979. The Communicative Approach to Language Teaching. Oxford: Oxford University Press. 
Brumfit, C.J.1979. “Communicative language teaching: an educational perspective”, in Brumfit \& Johnson, 1979: 183-191.

Carnap, R. 1938. "Foundations of logic and mathematics", in Neurath, Carnap \& Morris 1938, vol 1: 139-214.

Cole, P. \& Morgan, J.L. (eds.).1975. Syntax and Semantics Vol. 3: Speech Acts. New York: Academic Press.

Corder, S.P.1981.Error Analysis and Interlanguage. Oxford: Oxford University Press.

Coulthard, M.1977. An Introduction to Discourse Analysis. London: Longman. (2nd. ed. 1985).

Diller, K. C.1978. The Language Teaching Controversy. Rowley, Mass.: Newbury House.

Fillmore, C. J.1968. "The case for case", in Bach \& Harms 1968: 1-90.

Fillmore, C.J.1971."Verbs of judging: an exercise in semantic description", in Fillmore \& Langendoen 1971: 273-289.

Fillmore, C.J. \& Langendoen, D.T. (eds.). 1971.Studies in Linguistic Semantics. New York: Holt, Rinchart \& Winston.

Finnochiaro, M. \& Brumfit, C.1983. The Functional Approach. From Theory to Practice. Oxford: Oxford University Press.

Fries, C. C.1952. The Structure of English: An Introduction to the Construction of English Sentences. New York: Harcourt, Brace \& Co.

Grice, H. P.1957. "Meaning", reprinted in Steinberg \& Jakobovits 1971: 53-59.

Grice, H.P.1975."Logic and conversation", in Cole \& Morgan 1975.

Grimes, J. E. 1975. The Thread of Discourse. The Hague: Mouton.

Hymes, D. H. 1979."'On communicative competence". Extracts in Brumfit \& Johnson, 1979: 5-26.

Kiparsky, P. \& Kiparsky, C. 1971. "Fact", in Steinberg \& Jakobovits 1971: 345-369.

Labov, W. \& Fanshel, D.1977.Therapeutic Discourse: Psychotherapy as Conversation. New York: Academic Press.

Lado, R.1957. Linguistics Across Cultures: Applied Linguistics for Language Teachers. Ann Arbor: University of Michigan Press.

Lakoff, G. 1970. Irregularity in Syntax. New York: Holt, Rinehart \& Winston.

Leech, G. N.1983. Principles of Pragmatics. London: Longman.

Levinson, S. 1983. Pragmatics. Cambridge: Cambridge University Press.

Matlin, M. W. 1989. Cognition. Fort Worth: Holt, Rinehart \& Winston.

McCawley, J. D.1971."Prelexical syntax", in O'Brien 1971, 24: 19-33.

Morris, C. W. 1938. Foundations of the Theory of Signs. Reprinted in Morris, 1971.

Morris, C. W.1971.Writings on the General Theory of Signs. The Hague: Mouton.

Neurath, O.., Carnap, R. \& Morris, C.W. (eds.).1938.International Encyclopedia of Unified Science. Chicago: University of Chicago Press.

O'Brien, R. J. (ed.). 1971.Linguistics: Developments of the Sixties -Viewpoints of the Seventies. Washington, D.C.: Georgetown University Press.

Rumelhart, D.E. \& Ortony, A. 1977."The representation of knowledge in memory", in Anderson, Spiro \& Montague, 1977. 
Selinker, L. 1972. "Interlanguage”, IRAL, 10: 219- 231.

Slobin, D. I.1979. Psycholinguistics. Glenview, Ill.: Scott, Foresman \& Co. (2nd. ed.). Steinberg, D. \& Jakobovits, L. 1971. Semantics: AnInterdisciplinary Reader. Cambridge: Cambridge University Press.

van Dijk, T. A. \& Kintsch, W. 1983. Strategies of Discourse Comprehension. New York: Academic Press.

van Ek, J. A. 1975. The Threshold Level in a European Unit/Credit System for Modern Language Learning by Adults. Systems of Developement in Adult Language Learning. Strasbourg: Council of Europe.

Widdowson, H. G. 1984. Explorations in Applied Linguistics 2. Oxford: Oxford University Press.

Widdowson, H. G.1983. Learning Purpose and Language Use. Oxford: Oxford University Press.

Wilkins, D. A.1976. Notional Syllabuses. Oxford: Oxford University Press. 